\title{
Oral cancer knowledge, attitudes, and practices among dentists in Khartoum State, Sudan
}

\author{
Nada H. M. Ahmed and Sudeshni Naidoo
}

\begin{abstract}
The dental professions hold an important responsibility in the control of oral cancer and the early diagnosis highly depends on their knowledge. The present study was developed to assess the knowledge, attitude, and practice of dentists in Khartoum State regarding oral cancer prevention and early detection. An administered questionnaire was structured and sent to all licensed 130 dentists working in public dental clinics in Khartoum State. Responses to the questionnaire were analyzed using descriptive and analytical statistics. Although the majority of the dentists were knowledgeable about the major risk factors of oral cancer, more than half of the dentists reported they do not carry out any special examination to detect oral cancer in age 40 and above in asymptomatic patients. Dentists indicated their lack of training as the main barrier for conducting a comprehensive oral cancer examination. Interestingly, the vast majority of the dentists express their interest to have further oral cancer educational and training sessions. The findings of the present study suggested strongly that educational and training interventions are necessary to enhance preventive measures which may lead to reduce mortality and morbidity from oral cancer.
\end{abstract}

\section{Introduction}

Cancer of the lip and oral cavity are significant public health issue, with approximately 300,000 new cases per annum and 145,000 deaths worldwide [1]. Head and neck cancers rank the sixth most prevalent type of cancers, globally [2]. The incidence and mortality rates are rising in most regions, particularly developing countries. Their impact on individuals and communities from related pain, suffering, impairment of function and high treatment cost, morbidity and mortality are significant [3].

The risk factors for oral cancer may vary in different cultural and socioeconomic groups. Tobacco and alcohol intake are the traditional well-established risk factors; their synergistic effect induce a 24-fold increase in the risk of oral cancer [4]. Other predisposing factors include occupational exposure to carcinogens, dietary deficiencies, viral infections, in particular, human papilloma virus, known to have a high oncogenic potential [5]. In this regard, cancer prevention can be increased by raising public awareness of the dangers associated with these activities. 
Furthermore, the presentation of oral potentially malignant disorders (OPMDs) is considered significant risk factors to malignant transformation. The most common OPMDs are erythroplakia, oral leukoplakia, and oral lichen planus [6]. There perceived to be a general lack of knowledge vis-à-vis OPMDs and other oral mucosal lesions among many dentists and medical professionals [7].

In Sudan, oral cancer is one of the major public health problem; it ranks as the sixth among cancers $(6.1$ per 100,000) [8]; with an incidence rate of 920/year, comprising $9 \%$ of the cases reported in Africa [9]. The incidence rates of oral cancer are $3.7 \%$ for men and $2.6 \%$ for women [10]. The age standardized rate (ASR) of oral cancer in males in the Sudan is the second highest in the Middle East and North African region [11].

The consumption of local type of snuff known as Toombak, a very popular substance used by the Sudanese community, has a significant risk for the development of high proportion of oral squamous cell carcinoma among the Sudanese people [12] .It is a specific nitrose amine rich tobacco mixed with atron (sodium bicarbonate) and water; significantly implicated in the etiology of oral cancer [13] . The prevalence of Toombak use is around $45 \%$ among men aged 40 years and older and 10\% among women aged 60 years and older [14]. Regarding the stage of presentation, Osman et al. analyzed 261 cases of malignant tumors registered at Khartoum Dental Teaching Hospital. They observed that most of the patients attending the hospital at a very late stage (94\% of patients) were stage IV tumors [15].

While an earlier diagnosis of oral cancer, will lower the cost of treatment and significantly increase the probability of success of therapy and the rate of survival, with mini- mum deformity and impairment [16]. Moreover, and al- though the oral cavity is accessible of for examination for early detection, oral cancers remain a highly lethal disease with no significant improvements in the overall survival in the past decades [17].

Patients with possible oral lesions are often seen first by the general dental practitioners. They are in the unique position to be able to impact positively on the efforts of increasing early detection [18]. However, insufficient level of awareness has been reported to be the main reason for the lack of accurate and early diagnosis of oral cancers [19]. It is important that dentists carry out oral cancer examination as part of their clinical practice and be especially aware of the initial clinical signs associated with malignancy [20]. Patient education should be performed during all phases of dental treatment and the patient must be given all necessary knowledge in order to make in- formed decisions to protect and improve their own health care [21].

The understanding and evaluating of attitudes and awareness of dental healthcare professionals in any region is vital in assessing their effectiveness in the prevention and early detection of oral cancers and allows planning and designing of policies that are fit for purpose. This attitudes and awareness have been studied in many countries including the 
USA, Europe, Kuwait, Jordan, Yemen, and Iran [22-28]. Some of these studies revealed an insufficient lev- el of knowledge about oral cancers, including the lack of awareness of the risk factors and proper examination techniques [28]. These limitations in knowledge and diagnostic skills may hinder the recognition of lesions and contribute to the delayed oral cancer diagnosis. The present study is an attempt to determine dentists' knowledge, attitudes, and practices in the prevention and early detection of oral cancers, in Khartoum State. It is also aimed at evaluating continual education needs, with a focus on oral cancer risk factors and clinical diagnostic skills.

\section{Methodology}

Khartoum State provides dental services at governmental dental centers and polyclinics throughout seven governorates. This descriptive cross-sectional survey was conducted among dentists working in these clinics. The participants $(n=130)$ were registered general dental practitioners working in public dental clinics in Khartoum State. The list of invited participating dentists in this study was obtained from the Directorate of Oral Health, Ministry of Health Khartoum State. A survey was used to collect data and consisted of 28 questions, designed to investigate demographic attributes, oral cancer knowledge, and related dental practice characteristics. In addition, some questions examined the respondents' views regarding oral cancer prevention and early detection. A protocol was submitted for ethical approval, and the approvals were granted by the University of Western Cape Senate Research Ethics Committee and the Oral Health Directorate, Ministry of Health Khartoum State.

The data was captured, and basic descriptive analysis was made with data imported into SPSS ${ }^{\circledR}$ to perform complex statistical analyses. Descriptive statistics described demographic factors and independent $t$ test was used to determine associations between variables. The Mann-Whitney $U$ test was used to determine the relationship between nominal and the ordinal variables and Chi-square tests for other associations.

\section{Results}

The response rate of the study was 86.92, and the majority was females (68.1\%). Over approximately a third of participants (35.4\%) were in dental practice for less than 5 years and $42.5 \%$ graduated from dental school 6 to 10 years previously (Table 1 ).

\section{Oral Cancer Knowledge}

Over 90\% $(n=104)$ correctly identified squamous cell carcinoma as the most frequent histological type of oral cancer. 30.1\% identified the buccal mucosa, and $22.1 \%$ identifies the lips as the most common location. The tongue (20.4\%) and floor of the mouth (19.5\%), were almost equally identified by participants. 58.4\% (more than half of the respondents) reported the majority of oral cancers develop in patients be- tween the age of 40-59 years. However, only 40 respondents (35.4\%) correctly identified the age group of 60 years old and older, as the cohort in whom the majority of oral cancers are diagnosed. 


\section{Oral cancer Risk Factors}

Participants were asked to rank the risk factors of oral cancer from the most important to the least. 38.9\% reported tobacco and alcohol use as the most significant risk factors, while chronic diseases were reported by $60 \%$, as the second most common risk factors.

Table 1 Demographic and practice characteristics of respondents

\begin{tabular}{lll}
\hline Characteristics & Number & Percent (\%) \\
\hline Gender & & \\
Male & 36 & 31.9 \\
Female & 77 & 68.1 \\
$\quad$ Total & 113 & 100 \\
Time since graduation (years) & & \\
$3-5$ & 40 & 35.4 \\
$6-10$ & 48 & 42.5 \\
$11-15$ & 13 & 11.5 \\
More than 15 & 12 & 10.6 \\
Total & 113 & 100 \\
\hline
\end{tabular}

The majority correctly identified non-healing ulcers $(n=98,83.2 \%)$ and white or red patches ( $n=91,80.5 \%$ ), as early lesions of oral cancer (Fig. 1). A large number ( $n=98 ; 86.7 \%)$ correctly reported that pain would not usually associate with early presentation of oral cancer, and $43 \%$ indicated that a swelling might be an early symptom of oral cancer. A considerable number (70.8\%) were unaware that a low consumption of fruits and vegetables is also a risk factor for oral cancer. Almost two thirds (64.6\%) reported that family history of cancer was an increased risk factor of development of oral cancer. Viral infections (60\%) and poorly adjusted dentures (41.6\%) were also identified as risk factors.

\section{Oral Cancer Related Practice Oral Cancer Examination}

Interestingly, almost half (54\%) of the participating dentists reported that they do not carry out any particular examination to detect oral cancer, in asymptomatic patients (Fig. 2). Among those who reported that they do conduct a specific examination $(n=52 ; 46 \%)$, only seven of them $(14.3 \%)$ indicated taking a medical history. Fifty-one percent $(n=25)$ re- ported that they only make an intraoral examination to detect oral cancer, while $40.8 \%(n=20)$ perform an only extraoral examination. Fifty-seven percent reported to examine lymph nodes and a quarter would perform a biopsy and make a radiographic examination (Fig. 3).

Dentists who perform oral cancer examination were asked to estimate the relative time spent carrying out such an examination. Fifty-nine percent (59.6\%) reported more than $5 \mathrm{~min}, 34.6 \%$

\section{http://repository.uwc.ac.za}


3-5 min and 3.8\% less than $3 \mathrm{~min}$. The most important reasons given by participants of not providing oral cancer examinations were BI am not trained enough^ ${ }^{\wedge}(67.2 \%)$ and $14.8 \%$ reported, BIt's not necessary for all patients. ${ }^{\wedge}$

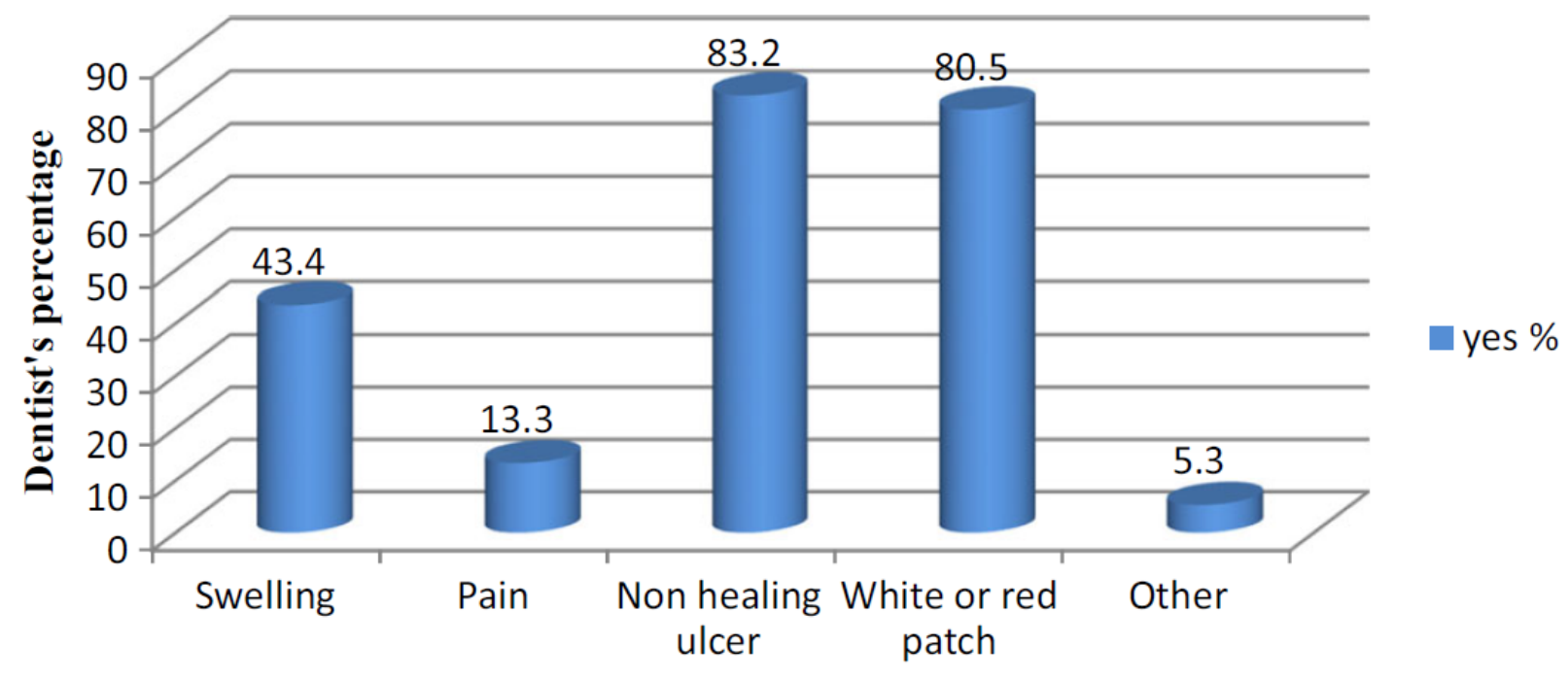

Fig. 1 Early presentation of oral cancer

\section{Risk Factors Counselling}

Regarding how frequently participating dentists provide counseling, 36.3\% ( $n=41)$ reported to having always discussed risk factors for oral cancer with their patients. Half of the participants who do not provide risk factors counseling felt they were not adequately trained to provide such service, and the maining quarter believed counseling not to be effective.

\section{Referral Practice}

$52.2 \%$ referred one to five patients to a specialist for a suspicious oral cancer lesion during the previous 12 months. $37.2 \%$ reported the referral was with a brief written letter, and $33.6 \%$ wrote a detailed letter that included a comprehensive descrip tion of the lesion and $6.2 \%$ verbally asked the patient to seek specialist advice. The majority (88.5\%) believed that referral guidelines would improve the quality of referrals to specialists.

\section{Oral Cancer Attitude and Training}

Only $26.7 \%$ perceived that their knowledge on oral cancer was as current and up-to-date and $35.3 \%$ reported that they did not believe they have the sufficient knowledge concerning oral cancer prevention. Nearly almost two thirds of the participating dentists (66.4\%) reported Bno ${ }^{\wedge}$ when asked if they had sufficient training to detect oral cancer lesions. 50.4\% $(n=57)$ believed screening for oral cancer through visual examination was an ineffective method for early detection (Table 2). 


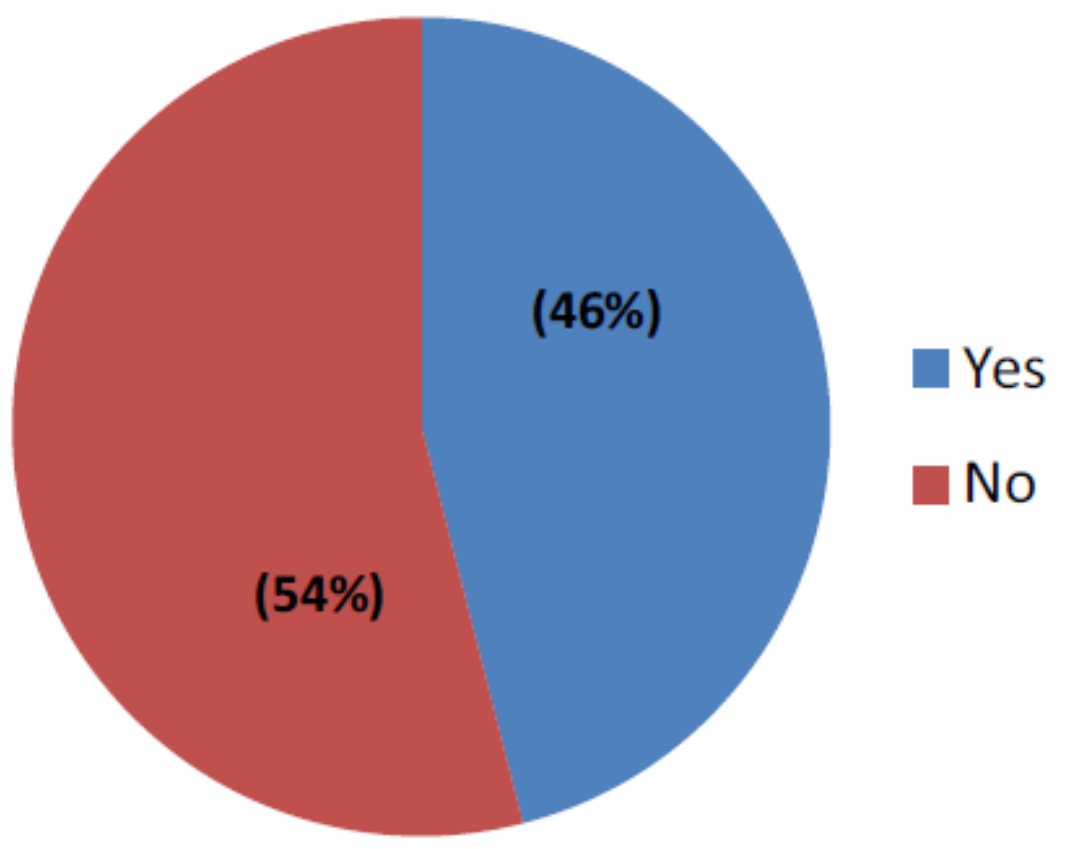

Fig. 2 Provision of oral cancer special examination (\%)

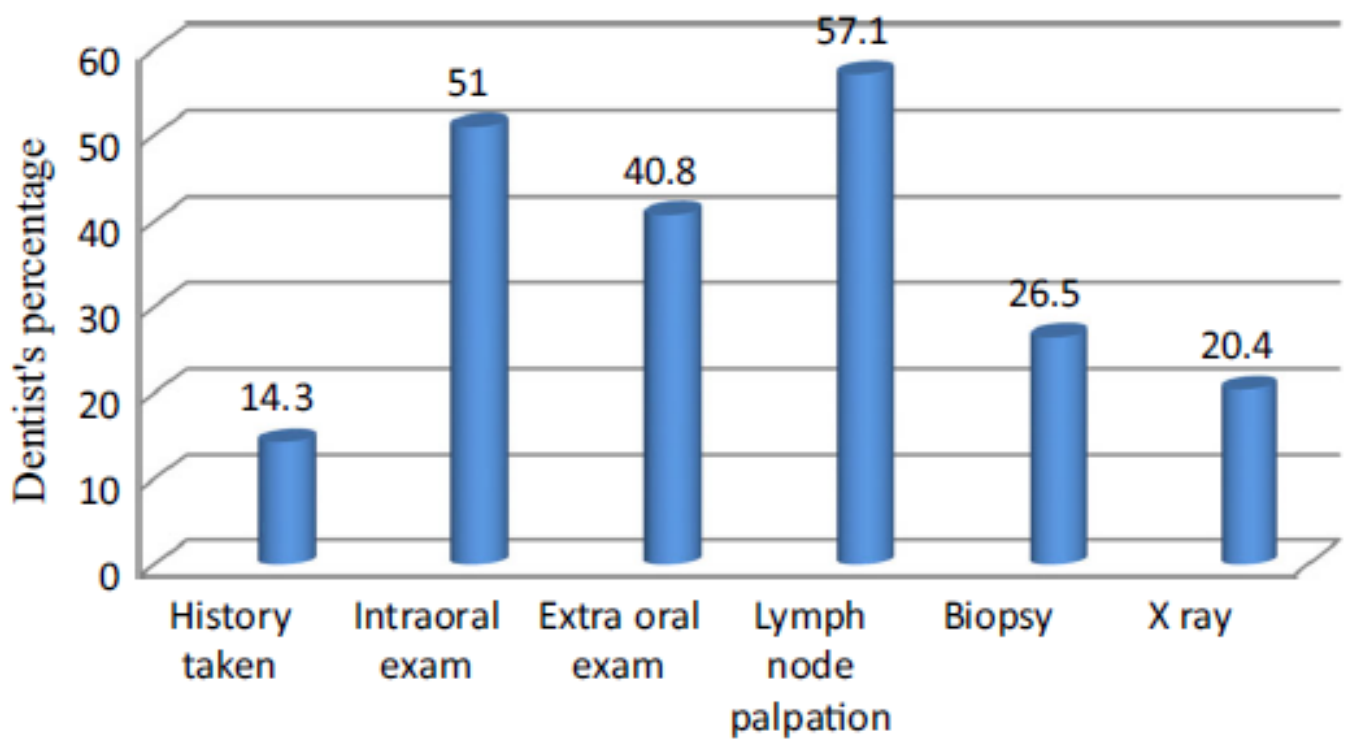

Fig. 3 Special test to detect oral cancer

\section{The Association between Demographic}

\section{Characteristics and Oral Cancer Knowledge}

There was a significant relationship between the time since graduation and the knowledge of the most common type of oral cancers $(p$ value $=0.020$ ). Recent graduates were more likely to identify the correct answer. When asked about continuing education, the vast majority (95.6\%) reported interest in further continuing education, regarding the prevention and early detection of oral cancer. 


\section{Discussion}

This study provided an overview of attitude and awareness of dentists in Khartoum state of early oral cancer detection and prevention. There was an $86.92 \%$ response rate, which is considered high compared to other similar studies from the USA, Kuwait, Yemen, and Iran [22, 24, 26, 27]. Squamous cell carcinoma (SCC) is the most common form of oral cancer, correctly identified by the majority of the participants similar to findings from the USA and Spain studies [22, 28]. Regarding oral cancer's frequent site, the participating dentists in this study identified the buccal mucosa and the lips as the two most common sites of oral cancer.

It is essential that dentists have the adequate knowledge of risk factors, to be able to provide appropriate oral cancer examination. Tobacco and alcohol are the main identifiable oral cancer risk factors; this was identified by the majority of the participants, similar to a study in Europe [28]. Interestingly, a considerable number (70.8\%) were not aware that a low consumption of fruits and vegetables is also a risk factor for oral cancer. This finding also concurs with a previous study from Ireland [29]. As in other studies from the USA and Germany [22, 23], a significant proportion of the participating dentists in the present study incorrectly identified a family history of oral cancer as a risk factor. There was (42\%) of the respondents had a misconception that ill-fitting dentures could also be a risk for oral cancer.

Although, recent reports indicate an increasing trend of oral cancer among young males, particularly cancer of the tongue, oral cancer remains largely, a disease of the elderly. In the present study, 35.4\% correctly identified the age group of 60 years and older, to develop oral cancer; this is considered lower number in comparison to similar studies carried out in Kuwait and UK $[24,29]$.

Leukoplakia and erythroplakia are the main OPMDs. In the present study over 80\% identified white or red patches, as the main precancerous lesions associated with oral neoplasia. Data from surveys in Jordan and Spain revealed that the majority of dentists were similarly aware that leukoplasia and erythroplasia are mucosal lesions associated with oral cancer [25, 28]. Pain, on the other hand, is not usually associated with the early presentation of oral cancer. This has been identified by the majority of participating dentists in this survey, similar to Decuseara and his colleagues in Ireland, who found most dentists knew that a patient is usually asymptomatic during the initial stages of the disease [29].

Furthermore, the majority of participants (80.5\%) categorized the survival rate of oral cancer as being between 4 and 6 years. In comparison, the majority of dentists surveyed in Germany, Kuwait, and Yemen knew that early detection improves survival rate [23, 24, 26]. Interestingly, more than half of participants reported not carry any particular examination to detect oral cancer for symptomatic 40 years and above patients. These findings are consistent with findings of a study from Iran [27]. Most important reasons given by respondents for not providing oral cancer examinations were BI am not trained enough^ and BIt's not necessary for all patients. ${ }^{\wedge}$ These findings are also consistent with a survey 
conducted in NY [22]. It highlights the need for further oral cancer education and training on early detection and diagnostic skills.

Although the fact that advice on smoking cessation and healthy eating are important, half of the participating dentists who do not provide risk factors counseling felt they were not trained enough to provide such advice. The remainder thought counseling would not be effective. This concurs with results reported in a study from Ireland [29]. In contrast, the majority of dentist in Yemen agreed that they were competent to counseling patients on tobacco cessation [26].

In our study, over half of the respondents referred to a specialist between one and five patients for a suspicious oral cancer lesion during the previous year. This number is lower than the reported in Spain where the mean annual number of referral is 3.8-7.4 patients [28]. Positively, the majority of participating dentists in the current study believed a development of referral guidelines could improve the quality of referrals to specialists.

Table 2 Dentist's beliefs about their knowledge on oral cancer prevention and diagnosis

\begin{tabular}{|c|c|c|c|c|c|c|c|}
\hline \multirow[t]{2}{*}{ Attitude } & \multicolumn{2}{|l|}{ Yes } & \multicolumn{2}{|c|}{ No } & \multicolumn{2}{|c|}{$\begin{array}{l}\text { Don't } \\
\text { know }\end{array}$} & \multirow[t]{2}{*}{ Total } \\
\hline & $n$ & $\%$ & $n$ & $\%$ & $n$ & $\%$ & \\
\hline $\begin{array}{l}\text { Your undergraduate training in the } \\
\text { diagnosis of oral cancer was } \\
\text { adequate }\end{array}$ & 31 & 27.4 & 75 & 66.4 & 7 & 6.2 & 113 \\
\hline $\begin{array}{l}\text { Screening for oral cancer through } \\
\text { visual examination is an } \\
\text { effective method for its early } \\
\text { detection }\end{array}$ & 52 & 46.0 & 57 & 50.4 & 4 & 3.5 & 113 \\
\hline $\begin{array}{l}\text { Development of referral guidelines } \\
\text { can improve the quality of } \\
\text { referrals }\end{array}$ & 100 & 88.5 & 4 & 3.5 & 9 & 8.0 & 113 \\
\hline $\begin{array}{l}\text { Interest on continuing education } \\
\text { regarding the examination and } \\
\text { early detection of oral cancer }\end{array}$ & 108 & 95.6 & 5 & 4.4 & 0 & 0 & 113 \\
\hline
\end{tabular}

\section{Discussion}

The current survey showed only $26.7 \%$ agreed that their knowledge on oral cancer is up-todate; this percentage is lower than the reported in a similar study in Yemen, where more than two thirds of the participants reported their knowl edge to current, as far as oral cancer is concerned [26]. 
A considerable number (66.4\%) felt that they had insufficient training to detect oral cancer lesions, in contrast to studies in Kuwait and Yemen where participants believe they had adequate training to examine patients for oral cancer [24, 26]. Furthermore, undergraduate training of oral cancer examination was reported to be adequate for the majority of the dentists in Kuwait [24]. However, a much lower figure was reported in this study, and only two thirds (27.4\%) believed that their undergraduate training in the diagnosis of oral cancer was adequate.

It is well established that continuous education can positively influence dentists' knowledge, attitudes, and practices [30]. It is encouraging that the vast majority of the respondents in the current study were interested in oral cancer continuing education, consistent with the reported by Alaizari and Al-Maweri, 2014, in Yemen [26].

There is a significant relationship between time since graduation and the knowledge of oral cancer. Recent graduates were more likely to demonstrate better knowledge, similarly reported in Ireland [29]. It highlights the need for dentists to be involved in continuous education in this area. The results of this study show that the knowledge, practices, and attitudes are consistent with the findings of previous surveys from different geographical regions. However, this should be interpreted in the context of potential methodological limitations. Variations in clinical practice regarding early detection suggest the need for established practice standards that can be introduced and reinforced through training programs in this region.

\section{Conclusion}

The study highlighted the importance of educational interventions to address the deficiency in awareness and practices in this region. Oral cancer preventive measures should be given a priority in any preventive strategy to reduce the burden of oral cancer in Sudan. The design of simple and uniform referral protocol for patients with suspected lesions may significantly reduce any potential delay in oral cancer diagnosis. There is also need to review the curriculum in dental schools to address any knowledge and training limitation so that future graduates are equipped with the appropriate attitude, awareness, and knowledge regarding oral cancer prevention and detection. 


\section{References}

1. Ferlay J, Soerjomataram I, Dikshit R, Eser S, Mathers C, Rebelo M, Parkin DM, Forman D, Bray F (2015) Cancer incidence and mortality worldwide: sources, methods and major patterns in GLOBOCAN 2012. Int.J Cancer 136(5):E359-E386. https://doi. org/10.1002/ijc.29210

2. Torre LA, Bray F, Siegel RL, Ferlay J, Lortet-Tieulent J, Jemal A (2015) Global cancer statistics, 2012. CA Cancer J Clin 65(2):87- 108. https://doi.org/10.3322/caac.21262

3. Natarajan E, Eisenberg E (2011) Contemporary concepts in the diagnosis of oral cancer and precancer. Dent Clin N Am 55(1): 63-88. https://doi.org/10.1016/j.cden.2010.08.006

4. Znaor A, Brennan P, Gajalakshmi V, Mathew A, Shanta V, Varghese C, Boffetta P (2003) Independent and combined effects of tobacco smoking, chewing and alcohol drinking on the risk of oral, pharyngeal and oesophageal cancers in Indian men. Int $J$ Cancer 105(5):681-686. https://doi.org/10.1002/ijc.11114

5. Ang KK, Harris J, Wheeler R, Weber R, Rosenthal DI, Nguyen-Tân PF (2010) Human papillomavirus and survival of patients with oropharyngeal cancer. N Engl $\mathrm{J}$ Med 363(1):24-35. https://doi. org/10.1056/NEJMoa0912217

6. Walsh T, Liu JL, Brocklehurst P, Glenny AM, Lingen M, Kerr AR, et al. 2013.Clinical assessment to screen for the detection of oral cavity cancer and potentially malignant disorders in apparently healthy adults. The Cochrane database of systematic reviews.; 11: Cdo10173. Epub 2013/11/22

7. Mortazavi H, Baharvand M, Mehdipour M (2014) Oral potentially malignant disorders: an overview of more than 20 entities. J Dental Res, Dental Clinics, Dental Prospects $8(1): 6-14$

8. Saeed IE, Weng HY, Mohamed KH, Mohammed SI (2014) Cancer incidence in Khartoum, Sudan: first results from the cancer registry, 2009-2010. Cancer Med 3(4):1075-1084. https://doi.org/10.1002/ cam4.254

9. International Agency for Research on Cancer (IARC). 2007. Cancer incidence in five continents. Vol IX. IARC Scientific Publications, No. 160, Lyon, IARC.

10. International Agency for research on cancer: GLOBOCAN 2008. Available from:http://globocan.iarc.fr/factsheets/populations/ factsheet.asp?uno=900\#MEN

11. Kujan O, Farah CS, Johnson NW (2017) Oral and oropharyngeal cancer in the Middle East and North Africa: incidence, mortality, trends, and gaps in public databases as presented to the Global Oral Cancer Forum. Trans Res Oral Oncol 2:1-9

12. Hassanin AA, Idris AM (2017) Attribution of oral cancer in the Sudan to Toombak dipping. Translational Research in Oral Oncol 2:1-5. https://doi.org/10.1177/2057178X16685729

13. Ahmed HG (2013) Aetiology of oral cancer in the Sudan. J Oral Maxillofac Res. 4(2):e3. https://doi.org/10.5037/jomr.2013.420.

14. Idris AM, Ibrahim YE, Warnakulasuriya KAAS et al (1998) Toombak use and cigarette smoking in the Sudan: estimates of prevalence in the Nile state. Prev Med 7:597-603 
15. Osman TA, Satti AA, Bøe OE, Yang YH, Ibrahim SO, Suleiman AM (2010) Pattern of malignant tumours registered at a referral oral and maxillofacial hospital in Sudan during 2006-2007. J Cancer Res Ther 6(4):473-477

16. Speight P, Warnakulasuriya S, Ogden G (2010) Early detection and prevention of oral cancer: a management strategy for dental practice. London, British Dental Association

17. Andisheh Tadbir A, Ebrahimi H, Pourshahidi S, Zeraatkar M (2013) Evaluation of levels of knowledge about etiology and symptoms of oral cancer in southern Iran. Asian Pac J Cancer Prev 14: 2217-2220

18. Kujan O, Sloan P (2013) Dilemmas of oral cancer screening: an update. Asian Pac J Cancer Prev 14(5):3369-3367. https://doi.org/ 10.7314/APJCP.2013.14.5.3369

19. Ahmed HG (2013) Aetiology of oral cancer in the Sudan. J Oral Maxillofac Res 4(2):e3. https://doi.org/10.5037/jomr.2013.4203

20.Gómez I, Warnakulasuriya S, Varela-Centelles PI, López-Jornet P, Suárez-Cunqueiro M, Diz-Dios P et al (2010) Is early diagnosis of oral cancer a feasible objective? Who is to blame for diagnostic delay? Oral Dis 16:333-342

21. Petersen PE. 2008. Oral cancer prevention and control-the approach of the World Health Organization. Oral Oncol.05.023

22. Gajendra S, Cruz GD, Kumar JV (2006) Oral cancer prevention and early detection: knowledge, practices and opinions of oral health care providers in New York state. J Cancer Educ 21(3):157-162. https://doi.org/10.1207/s15430154jce2103_14

23. Hertrampf K, Wiltfang J, Koller M, Klosa K, Wenz HJ (2010) Dentists' perspectives on oral cancer: a survey in Northern Germany and a comparison with international data. Eur J Cancer Prev 19(2):144 - 152. https://doi.org /10.1097/CEJ. obo13e3283362a69

24. Joseph BK, Sundaram DB, Sharma P (2011) Oral cancer awareness among dentists in Kuwait. Med Princ Pract 21(2):164-170. https:// doi.org/10.1159/000333543

25. Hassona Y, Sawair F, Baqain Z, Maayta W, Shahin A, Scully C (2015) Oral cancer early detection-a pressing need for continuing education in Jordan. Asian Pac J Cancer Prev 16(17):17,7727-17, 7730

26. Alaizari NA, Al-Maweri SA (2014) Oral cancer: knowledge, practices and opinions of dentists in yemen. Asian Pac $J$ Cancer Prev 15(14):5627-5631. https://doi.org/10.7314/APJCP.2014.15.14. 5627

27. Razavi SM, Zolfaghari B, Foroohandeh M, Doost ME, Tahani B (2013) Dentists' knowledge, attitude, and practice regarding oral cancer in Iran. J Cancer Educ 28(2):335-341. https://doi.org/10. 1007/s13187-013-0460-6

28. López-Jornet P, Camacho-Alonso F, Molina-Miñano F (2010) Knowledge and attitudes about oral cancer among dentists in Spain. J Eval Clin Pract 16(1):129-133. https://doi.org/10.1111/j. 1365-2753.2009.01132.x

29. Decuseara G, MacCarthy D, Menezes G (2011) Oral cancer: knowledge, practices and opinions of dentists in Ireland. J Ir Dent Assoc 57(4):209-214

30. Silverman S Jr, Rankin KV (2010) Oral and pharyngeal cancer control through continuous education. J Cancer Educ 25:277-278 